\title{
DNA Methylation Changes in the IGF1R Gene in Birth Weight Discordant Adult Monozygotic Twins
}

\author{
Pei-Chien Tsai, ${ }^{1}$ Jenny Van Dongen, ${ }^{2}$ Qihua Tan, ${ }^{3,4}$ Gonneke Willemsen, ${ }^{2}$ Lene Christiansen, ${ }^{3}$ \\ Dorret I. Boomsma, ${ }^{2}$ Tim D. Spector, ${ }^{1}$ Ana M. Valdes, ${ }^{1,5, *}$ and Jordana T. Bell ${ }^{1, *}$ \\ ${ }^{1}$ Department of Twin Research \& Genetic Epidemiology, King's College London, London, UK \\ ${ }^{2}$ Department of Biological Psychology, VU University Amsterdam, Amsterdam, the Netherlands \\ ${ }^{3}$ Epidemiology, Biostatistics and Biodemography, Institute of Public Health, University of Southern Denmark, Denmark \\ ${ }^{4}$ Department of Clinical Genetics, Odense University Hospital, Odense, Denmark \\ ${ }^{5}$ School of Medicine, University of Nottingham, Nottingham, UK
}

\begin{abstract}
Low birth weight (LBW) can have an impact on health outcomes in later life, especially in relation to predisposition to metabolic disease. Several studies suggest that LBW resulting from restricted intrauterine growth leaves a footprint on DNA methylation in utero, and this influence likely persists into adulthood. To investigate this further, we performed epigenome-wide association analyses of blood DNA methylation using Infinium HumanMethylation450 BeadChip profiles in 71 adult monozygotic (MZ) twin pairs who were extremely discordant for birth weight. A signal mapping to the IGF1R gene (cg12562232, $p=2.62 \times$ $10^{-8}$ ), was significantly associated with birth weight discordance at a genome-wide false-discovery rate (FDR) of 0.05 . We pursued replication in three additional independent datasets of birth weight discordant $M Z$ pairs and observed the same direction of association, but the results were not significant. However, a meta-analysis across the four independent samples, in total 216 birth-weight discordant MZ twin pairs, showed a significant positive association between birth weight and DNA methylation differences at IGF1R (random-effects meta-analysis $p=.04$ ), and the effect was particularly pronounced in older twins (randomeffects meta-analysis $p=.008,98$ older birth-weight discordant MZ twin pairs). The results suggest that severe intra-uterine growth differences (birth weight discordance $>20 \%$ ) are associated with methylation changes in the IGF1R gene in adulthood, independent of genetic effects.
\end{abstract}

Keywords epigenome-wide association scans, birth weight, discordant monozygotic twin pairs

Fetal programming, or the adaptive responses of the fetus to a variety of environmental factors, and the consequences of mismatch between prenatal and post-natal environments are now known to shape development and metabolism, potentially contributing to adult-onset disease (Barker \& Osmond, 1986; Barker et al., 1989; Barker et al., 1993a; 1993b). LBW is defined as birth weight lower than 2,500 grams in singleton births (World Health Organization, 1992). Studies have linked LBW to childhood mortality (McCormick, 1985), morbidity (Wu et al., 2011), and childhood asthma (Brooks et al., 2001). LBW is also associated with disorders progressing into adulthood, such as metabolic syndrome (Fagerberg et al., 2004), type 2 diabetes (Johansson et al., 2008), cardiovascular diseases (Leeson et al., 2001), respiratory diseases (Walter et al., 2009), and depression (Thompson et al., 2001).

Two important factors that influence birth weight are the length of the gestation period and the prenatal growth rate. Other modifiable factors exist in utero, such as maternal smoking during pregnancy (Ward et al., 2007) and maternal health and nutrition (e.g., caloric intake; Kramer, 1987a, 1987b). Several genetic variants have been associated with birth weight (Freathy et al., 2010; Horikoshi et al., 2013); however, these show only a modest genetic contribution to the total variance in birth weight (Barker, 2004; Battaglia \& Lubchenco, 1967; Freathy et al., 2010; Heijmans et al., 2008; Horikoshi et al., 2013; Jarvelin et al., 2004; McIntire et al., 1999). Heritability estimates for birth weight from twin and family studies have given highly variable results,

RECEIVED 8 September 2015; ACCEPTED 1 October 2015. First published online 13 November 2015.

ADDRESS FOR CORRESPONDENCE: Jordana T. Bell, Department of Twin Research and Genetic Epidemiology, King's College London, St Thomas' Hospital Campus, 3rd Floor South Wing Block D, Westminster Bridge Road, London SE1 7EH. E-mail: jordana.bell@kcl.ac.uk

${ }^{*}$ These authors contributed equally. 
ranging from $15 \%$ to $72 \%$ (Baird et al., 2001; Clausson et al., 2000; Gielen et al., 2008; Lunde et al., 2007; Magnus, 1984a, 1984b; Magnus et al., 2001; Mook-Kanamori et al., 2012). Given the high relevance of LBW to health throughout the life course, the molecular links between birth weight and age-related disease has attracted much research.

LBW may be associated with epigenetic variation, and recent evidence suggests that maternal nutrition intake is a crucial factor determining the extent of this impact (Amarasekera et al., 2014; Dominguez-Salas et al., 2014; Fernandez-Twinn \& Ozanne, 2010). A number of environmental factors, including smoking, stress, hypoxia, a diet high in methyl-donor nutrients, such as folic acid, folate, and vitamin B during pregnancy, may alter gene expression during early embryonic development when epigenomes are becoming established. For example, DNA methylation levels at the IGF2 gene were reported to be significantly lower in adults who were in utero during the Dutch Hunger Winter Famine (1944-1945) when compared to same-sex siblings in utero unexposed to famine (Heijmans et al., 2008). Other candidate gene studies have also reported birth weight related methylation differences in imprinted genes that play a role in fetal growth, such as IGF2 and H19 (Hoyo et al., 2012; Steegers-Theunissen et al., 2009) and in nonimprinted genes such as the glucocorticoid receptor NR3C1 (Filiberto et al., 2011; Mulligan et al., 2012). More recently, epigenome-wide association studies (EWAS) have been performed for birth weight using the Infinium HumanMethylation27 BeadChip (Infinium 27K; Adkins et al., 2012; Banister et al., 2011; Fryer et al., 2011; Straughen et al., 2015) and the Infinium HumanMethylation450 BeadChip (Infinium 450K; Engel et al., 2014; Simpkin et al., 2015) methylation platforms (Illumina Inc, San Diego, CA). The results show that methylation at a few CpG sites appears to be associated with birth weight, but the magnitude of methylation differences tends to be small. For example, in one study a $10 \%$ difference in (untransformed) DNA methylation levels at the majority of birth weight associated CpG sites was reported to correspond to covariate-adjusted birth weight differences of 200 grams or less, with few exceptions (Engel et al., 2014). One longitudinal study in singletons found that birth weight associated methylation changes are restricted to individuals of a younger age, and that these effects did not persist into older age (Simpkin et al., 2015). However, all of these studies were performed in unrelated subjects, where maternal environment and exposures are difficult to adequately account for.

Here, we explored DNA methylation differences in MZ twins discordant for birth weight. The discordant MZ twin study design can control for many potential epigenetic confounders; specifically, differences in genetic background, shared early life environmental exposures, age, sex, and cohort effects. Although MZ twins do not necessarily share the same in utero environment, they are more closely matched than unrelated individuals, and they offer a unique op- portunity to study the link between early life factors and adult life health. Birth weight discordance in twins may arise through mechanisms not experienced by singletons (Lopriore et al., 2003), but shared results linking birth weight to cardiovascular health are identified in both twins and singletons (McNeill et al., 2004). A recent longitudinal study in twins from birth to 18 months explored genomewide DNA methylation patterns in buccal epithelium (Martino et al., 2013). The authors observed that the extent of weight discordance in twins was greater at birth compared to at 18 months, which they termed a convergence in discordance. In contrast, the extent of methylation discordance in twins over time exhibited a twin-pair-specific pattern, where some twin pairs showed epigenetic convergence over time, some pairs showed epigenetic divergence of time, and other pairs remained equally discordant at birth and at 18 months. The observation that both weight and epigenetic profiles can exhibit convergence in twin pair discordance over time suggests that epigenetic studies of birth weight in twins may yield fruitful for uncovering epigenetic signatures of birth weight, but that the observed effects should be explored further in twin samples obtained at birth, ideally in a longitudinal study design.

Several studies in twins have explored epigenetic and gene expression profiles in relation to birth weight or maternal factors strongly associated with birth weight (Gordon et al., 2011, 2012; Loke et al., 2013; Ollikainen et al., 2010; Souren et al., 2013; Tan et al., 2014). To date, three EWAS have focused on MZ twins discordant for birth weight. The first profiled DNA methylation using the Infinium $27 \mathrm{~K}$ array in 14 birth weight discordant MZ twin pairs (Gordon et al., 2012). One differential methylation signal was identified in the $A P O L D 1$ gene, which has previously been linked to metabolic phenotypes. The effects appeared to be specific to human umbilical vascular endothelial cells, and significant changes were not observed in placental tissue or cord blood mononuclear cells. The second study used Infinium $450 \mathrm{~K}$ to compare the methylation levels in buccal samples from 17 monochorionic MZ adult twins (Souren et al., 2013). By comparing the methylation differences between the heavy and light co-twins and adjusting the methylation levels with leukocyte subtypes, the authors identified 3,153 birth weight differential methylation sites at $p<.01$ and 45 of these showed absolute methylation differences greater than $5 \%$, but none of these changes reached genome-wide significance. The third more recent study in blood Infinium $450 \mathrm{~K}$ profiles from 150 adult $\mathrm{MZ}$ twin pairs also found no genome-wide associations with birth weight in the overall sample, but analysis of 28 extremely birth weight discordant MZ twins pairs identified three significant differentially methylated sites, where the effects appeared to be restricted to specific age groups; that is, the intra-pair differential methylation effect either increased or decreased with age (Tan et al., 2014). In this study, we explored the hypothesis that birth weight differences in $\mathrm{MZ}$ twins are 
reflected in the whole blood epigenome and persist into adulthood.

\section{Materials and Methods}

\section{Study Population, Phenotype, and Covariate Data}

Discovery sample: TwinsUK cohort. We used phenotypes and DNA methylation data generated on individuals from the TwinsUK cohort. The cohort was established in 1992 and recruited MZ and DZ same-sex twins (Moayyeri et al., 2013). The majority of participants are healthy female Caucasians (age range from 16 to 98 years old). There are over 13,000 twin participants across the United Kingdom and many have returned for multiple visits. We selected $71 \mathrm{MZ}$ twin pairs from the cohort who were extremely discordant for birth weight (see discordance criteria below) for DNA methylation profiling.

Each subject's blood sample was collected during a clinical visit, along with a clinical questionnaire that included information on self-reported birth weight, medical history, and measures for height, weight, and BMI. The age at DNA extraction was taken into account as a covariate since methylation levels can change over time (Levesque et al., 2014; Martino et al., 2013). Additional covariates, such as smoking status and alcohol consumption, were collected by self-reported questionnaires. Subjects were categorized as non-smokers, ex-smokers, and current smokers, and alcohol consumption data was summarized as grams/day intake. Participants were asked for their weekly average amount of alcohol intake (e.g., wine, beer, spirits, and liqueurs) and alcohol consumption data were then summarized as units per week, and then converted to grams/day (one unit of alcohol in the UK is defined as 7.9 grams; Brennan et al., 2014). Previous studies have reported that the composition of white blood cells (WBC) can influence DNA methylation levels (Houseman et al., 2012). We obtained six cell count estimates, including: CD8 $+\mathrm{T}$ cells, CD4+ T cells, natural killer cells, CD19+ B cells, CD14+ monocytes, and granulocytes using previous methods (Houseman et al., 2012).

Birth weight discordance for each twin pair was calculated as the birth weight ratio (BWratio; Martino et al., 2013; Tan et al., 2014) as follows:

$$
B W \text { ratio }(\%)=\frac{\max (B W)-\min (B W)}{\min (B W)} \times 100
$$

We considered birth weight discordant $\mathrm{MZ}$ twins where $\mathrm{BW}$ ratio $>20 \%$.

\section{Replication samples 1 and 2: Danish Twin Registry} (DTR). The Danish Twin Registry was established in the 1950s and has collected information on over 88,000 twin pairs born in Denmark. Here, we used birth weight and whole blood DNA methylation Infinium $450 \mathrm{~K}$ data from 27 old birth weight discordant MZ twin pairs with BWratio $>20 \%$ (replication sample 1, DTR old), and from 29 young birth weight discordant MZ twin pairs with BWratio > 20\% (replication sample 2, DTR young). The phenotype and methylation data in these samples have previously been described (Frost et al., 2012; Tan et al., 2014). Birth weight information in the DTR old sample was derived from midwife reports, and information in the DTR young sample was obtained from the Danish Birth Record Registry. The methylation data were first normalized using subset quantile within-array normalization method (Maksimovic et al., 2012) and then normalized to a normal distribution using a logit transformation. The methylation residuals were taken after adjusting for covariates such as age, sex, and blood cell composition. The resulting intra-pair methylation differences then correlated to the BWratio using Spearman's correlation test.

Replication sample 3: Netherlands Twin Register (NTR). The Netherlands Twin Register was established in 1987 and the NTR survey studies and the NTR BioBank project are described elsewhere (Boomsma et al., 2002, 2006; Willemsen et al., 2010, 2013). Genome-wide methylation in blood was profiled using the Infinium $450 \mathrm{~K}$ platform (Van Dongen et al., 2015). Data on birth weight were obtained from self-report by the twins themselves or their parents. Data collected across multiple surveys and projects were combined and consistency across family members and time was checked. When multiple data points differed by less than 200 grams, the average was taken, and larger differences data were excluded. Here, we analyzed birth weight and blood DNA methylation data that were available for 89 birth weight discordant MZ twin pairs, with BWratio $>20 \%$. The methylation data were first subject to functional normalization (Fortin et al., 2014) and then transformed to follow the normal distribution. A linear regression was used to fit the data to take into account the following covariates: sex, age, methylation array row, methylation plate, smoking status (non-smokers, ex-smokers, and current smokers), neutrophil percentage, monocyte percentage, and eosinophil percentage. The resulting residuals were used to calculate intra-pair methylation differences, and these were correlated with BWratio using Spearman's correlation.

\section{DNA Methylation}

In the discovery sample, DNA was extracted from whole blood and bisulfite converted prior to DNA methylation analysis using the DNeasy kit (Qiagen, Inc.). Bisulfite modification was performed using 96 well EZ DNA methylation kit (Zymo Research) with 750 ng of DNA sample. Methylation levels were detected using the Infinium $450 \mathrm{~K}$ and the intensity images captured by GenomeStudio (2010.3) Methylation module (1.8.5) software. Details of the method are described elsewhere for a subset of our sample (Tsaprouni et al., 2014). The beta mixture quantile dilation (BMIQ) method was performed to correct for the technical issues caused by the two Illumina probe types (Teschendorff et al., 
2013). DNA methylation probes that mapped to multiple locations (with exact sequence match and within up to two base pair mismatches) to the reference sequence were removed. Probes for which more than $1 \%$ subjects had detection $p$ value $>.05$ were also removed. A background signal correction by removing the signal detected from a negative control samples were applied to the methylation data using R package 'Minfi' (Aryee et al., 2014). Subjects with over $5 \%$ missing probes were removed. We only considered autosomal probes in the analysis because the discovery sample consisted of females only, while the replication samples included both males and females. The final methylation data contained 442,307 probes with no missing values. Because beta values are overall not normally distributed, probe data was transformed using quantile normalization to a standard normal distribution.

\section{Methylation Analysis}

The association between DNA methylation and birth weight was investigated for all probes in the discovery dataset of 71 birth-weight discordant MZ twins. Principal component analysis (PCA) was applied to the methylation data to identify batch effects by correlating each potential covariate with the first two PCs, which together explained $23.7 \%$ of the variance. A linear mixed effect regression model was applied to the available methylation data, and methylation residuals were obtained after adjusting for covariates. The covariates in the model included age, WBC count estimates, smoking status (non-smokers, ex-smokers, and current smokers), alcohol consumption (grams/day), methylation plate, and position on the plate as fixed effects, and family and zygosity as random effects.

To explore the association between birth weight discordance and DNA methylation in the MZ twin samples, we first considered birth weight as a continuous trait. Intra-pair methylation differences were calculated by subtracting the methylation levels from the larger twin minus their smaller co-twin. The methylation differences were then correlated with the birth weight discordance to identify differential methylation sites, and the Spearman's correlation coefficients and $p$ values were reported at each CpG site. In addition, we also assessed whether significant DNA methylation differences exist between the larger and smaller co-twin in the sample, irrespective of the exact birth weight values. In this case, twins were assigned to two groups (based on larger and smaller birth weight) and methylation levels were compared within-pairs using the Wilcoxon signed-rank test. The MZ twin continuous analyses were also pursued at the topranked probe in replication samples from the Netherlands and from Denmark.

\section{Meta-Analysis of Twin Datasets}

We analyzed the top-ranked signal in the discovery and replication datasets using a meta-analysis of the correlation coefficients, performed using the R packages 'metacor'
(Laliberté, 2011) and 'Mac' (Re \& Hoyt, 2012). We first measured the diversity index of the studies $\left(I^{2}\right)$ to detect the homogeneity among the studies using the 'Mac' package (Higgins \& Thompson, 2002) and then performed the meta-analysis based on either the random-effects or the fixed-effects model (Schulze, 2004).

\section{Results}

\section{Demographic Characteristics of the Twin Samples}

The descriptive characteristics of the discovery cohort and the replication cohorts are shown in Table 1. The discovery sample for epigenome-wide analysis consisted of 71 birth weight discordant MZ female twin pairs (mean age 55.4 years, age range: $34.2-77.7$ years) without severe poor health conditions, including cancer and type 2 diabetes, at the age of DNA sample collection. Birth weight discordance was defined as BWratio greater than 20\% (see Methods), and the discovery mean BWratio was $35.0 \%$ (range: $20.4-71.3 \%$ ), corresponding to a mean absolute birth weight difference of $943 \mathrm{~g}( \pm 562 \mathrm{~g})$. Subjects with a smaller birth weight were significantly shorter in adulthood height $(p=4.88 \times$ $\left.10^{-9}\right)$, as observed in previous studies, but no significant association was found with BMI $(p=.947)$, and marginal significance was obtained with adult weight $(p=.036)$. No significant association was observed with age at blood sampling and BWratio. We calculated the intra-pair correlation in genome-wide DNA methylation Infinium $450 \mathrm{~K}$ profiles in the discovery sample of $71 \mathrm{MZ}$ pairs, and observed high correlation (correlation coefficient $=0.997$, range: $0.987-$ 0.999), which is consistent with previous studies (Bell et al., 2012; Souren et al., 2013; van Dongen et al., 2014) and suggests minimal within-pair methylation differences.

We pursued replication of the top-ranked LBWassociated DNA methylation signal found in the discovery sample in three additional independent samples of birth weight discordant MZ twin pairs from Denmark (replication samples 1 [DTR old] and 2 [DTR young]) and the Netherlands (replication sample 3 [NTR]; Table 1). In each case, we only selected birth weight discordant MZ twin pairs with BWratio greater than $20 \%$. However, the extent of birth-weight discordance in the replication samples was attenuated compared to the discovery cohort. The replication samples consisted of adult MZ twins either younger (NTR, DTR young) or older (DTR old) than the mean age of the discovery cohort, and contained individuals of both sexes.

\section{Epigenome-Wide Analysis of Birth Weight Discordant Twins}

Epigenome-wide analyses in the discovery sample of $71 \mathrm{MZ}$ twin pairs compared methylation differences within pairs to BWratio using Spearman's correlation (Figure 1A). One CPG site passed genome-wide significance based on FDR of 0.05 . The signal was obtained at CpG site cg12562232 
TABLE 1

Characteristics of Four Birth Weight Discordant MZ Twin Samples

\begin{tabular}{|c|c|c|c|c|}
\hline Cohort & TwinsUK & DTR old & DTR young & NTR \\
\hline$N$ & 71 & 27 & 29 & 89 \\
\hline \multicolumn{5}{|l|}{ Gender } \\
\hline Female & $71(100 \%)$ & $13(48.1 \%)$ & 15 (51.7\%) & 66 (74.2\%) \\
\hline Male & 0 & 14 (51.9\%) & 14 (48.3\%) & $23(25.8 \%)$ \\
\hline Age & $55.4(9.84)$ & $64.1(4.7)$ & $33.8(1.6)$ & $34.3(12.1)$ \\
\hline \multicolumn{5}{|l|}{ Birth weight } \\
\hline BWratio(\%) & $35.0(12.5)$ & $25.0(5.6)$ & $28.2(7.8)$ & $30.3(9.0)$ \\
\hline Range (g) & $908,5,136$ & $1,100,3,400$ & $1,125,4,125$ & $1,000,4,430$ \\
\hline
\end{tabular}

Note: $N=$ number of $\mathrm{MZ}$ twin pairs; Age = DNA extraction age; BWdiff = absolute birth weight difference within twin pairs (g); BWratio = birth weight ratio within twin pairs (\%); NTR = Netherlands Twin Registry; DTR = Danish Twin Register.
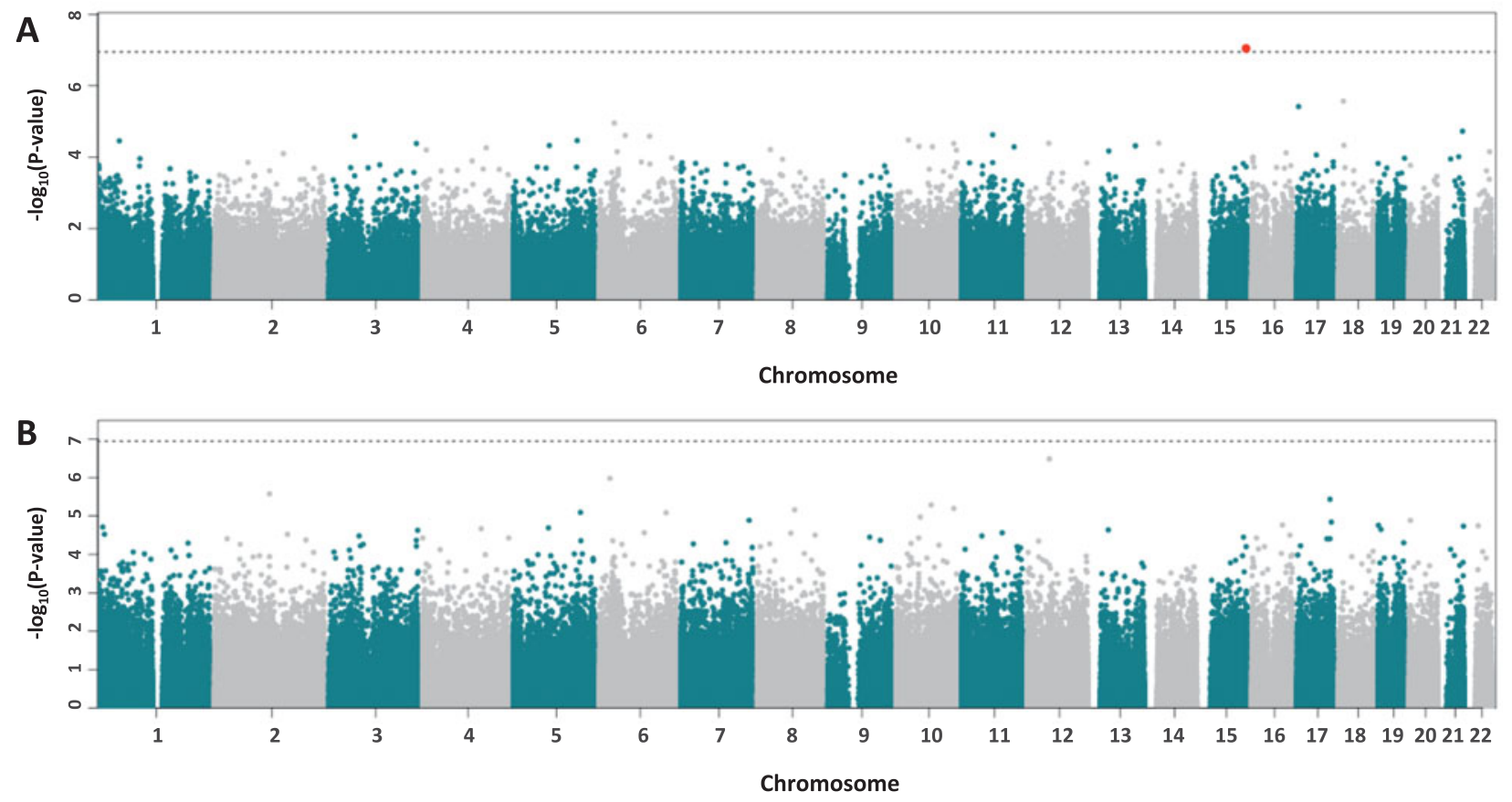

FIGURE 1

(Colour online) Manhattan plots of birth weight EWAS in $71 \mathrm{MZ}$ discordant twins using (A) BW as a continuous trait, and (B) BW as a categorical trait. The red point above the $5 \%$ FDR line (grey dashed line) is the birth weight differential methylation signal at cg12562232 in the IGF1R gene.

(correlation coefficient $=0.603,95 \%$ CI: $0.430-0.719, p=$ $\left.2.62 \times 10^{-8}\right)$, which is located in intron 2 of the IGF1R gene on chromosome 15. At this site there was a positive correlation between intra-pair methylation differences and BWratio (Figure 2A). We also checked the other $128 \mathrm{CpG}$ sites within the promoter or gene body of the IGF1R gene for association with birth weight. Although none of these CpG sites reached genome-wide significance, one signal located in the IGF1R gene body ( $\operatorname{cg} 23091737)$, and within $5 \mathrm{~kb}$ from cg12562232, surpassed nominal significance in the same direction of association. Aside from IGF1R, the next top-ranked signals were obtained at cg12049992 in the FAM $38 B$ gene (correlation coefficient $=-0.519, p=$ $\left.3.49 \times 10^{-6}\right), \operatorname{cg} 12508856$ in the KIF13B gene (correlation coefficient $\left.=-0.510, p=5.52 \times 10^{-6}\right), \operatorname{cg} 12391576$ in the HLA-DPA1 gene (correlation coefficient $=0.508, p=6.07$ $\times 10^{-6}$ ), and $\operatorname{cg} 26313699$ in the OR1G1 gene (correlation coefficient $=-0.507, p=6.29 \times 10^{-6}$ ) but the results were not genome-wide significant $(\mathrm{FDR}=0.57$ ).

We also explored intra-pair methylation differences between the larger twin and their smaller co-twin, without considering the exact value of the birth weight discordance. The epigenome-wide analysis in this category was performed using non-parametric paired tests and no CpG sites reached genome-wide significance (Figure 1B). The top-ranked signal in these analyses was obtained at $\mathrm{CpG}$ site cg24296900 located $1.5 \mathrm{~kb}$ from the transcription start site of the TUBA1 C gene $\left(p=3.27 \times 10^{-7}\right)$. 
TABLE 2

Random-Effects Meta-Analysis Results in the IGF1R Gene (cg12562232)

\begin{tabular}{|c|c|c|c|c|}
\hline Cohort & $N$ & Test statistics & $95 \% \mathrm{Cl}$ & $p$ value \\
\hline TwinsUK & 71 & $\rho=0.603^{a}$ & $0.430,0.733$ & $2.62 \times 10^{-8}$ \\
\hline DTR old & 27 & $\rho=0.263^{\mathrm{a}}$ & $-0.130,0.585$ & 0.186 \\
\hline DTR young & 29 & $\rho=-0.027^{a}$ & $-0.390,0.343$ & 0.888 \\
\hline NTR & 89 & $\rho=0.161^{a}$ & $-0.049,0.357$ & 0.132 \\
\hline Meta-analysis: all twins & 216 & $\rho=0.282^{b} R^{2}=83.41 \%^{c}$ & $-0.037,0.550$ & 0.041 \\
\hline Meta-analysis: old twins & 98 & $\rho=0.474^{b} P^{2}=66.17 \%^{c}$ & $0.099,0.731$ & $7.55 \times 10^{-3}$ \\
\hline
\end{tabular}

Note: aSpearman's correlation coefficient.

${ }^{b}$ mean correlation coefficient.

${ }^{c}$ Heterogeneity Index.

A

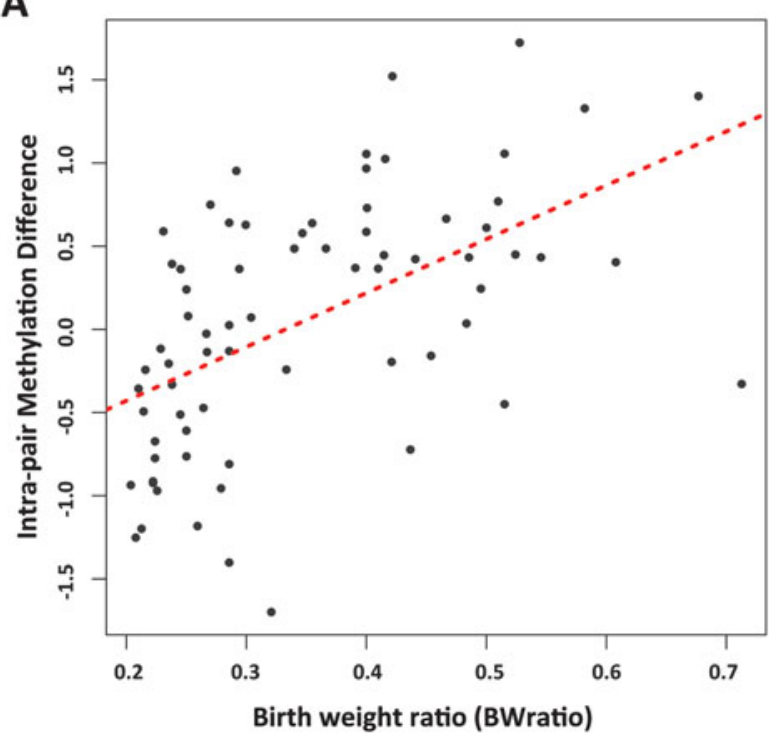

B

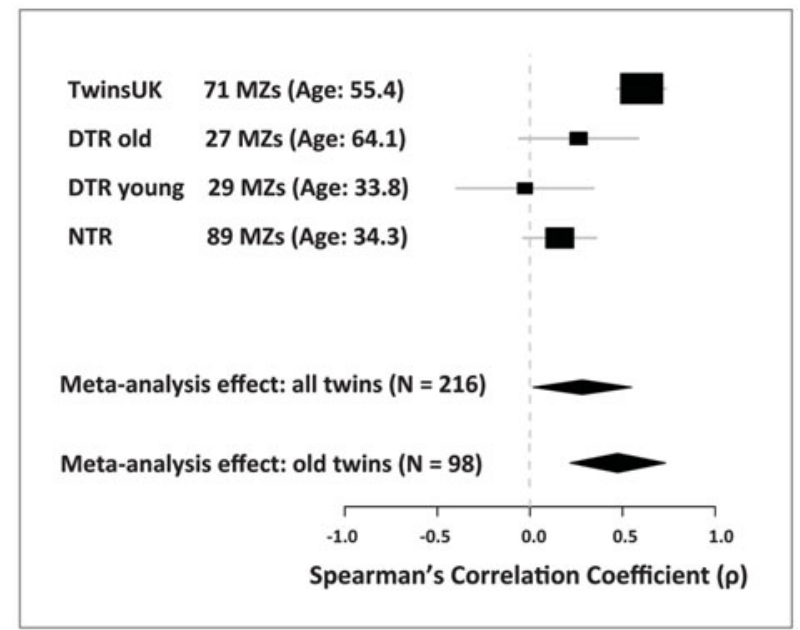

FIGURE 2

(Colour online) Birth weight differential methylation signal in IGF1R. (A) The correlation between the covariate-adjusted intra-pair methylation residual differences and the birth weight ratio in 71 birth weight discordant MZ pairs from TwinsUK. Each dot represents a single pair. (B) Forest plot of the meta-analysis results at the IGF1R gene in four birth weight discordant MZ twin samples from the United Kingdom (TwinsUK), Denmark (DTR old and DTR young), and the Netherlands (NTR). Random-effects meta-analysis estimates are shown for the results encompassing all four samples, as well as the two older twin samples from TwinsUK and DTR old.

\section{Replication of the IGF1R Signal}

In order to try and replicate the association between birth weight discordance and IGF1R methylation levels, we performed a similar analysis in three independent $\mathrm{MZ}$ twin samples from the Danish $(N=29$ and $N=27 \mathrm{MZ}$ pairs $)$ and the Netherlands ( $N=89 \mathrm{MZ}$ pairs) twin registries. DTR samples were stratified by age at recruitment, and therefore we performed the correlation test separately in the young $(N=29)$ and old $(N=27)$ twins. In contrast to the TwinsUK sample, the replication samples differed in mean age, contained male subjects, and were overall less discordant for birth weight (Table 1). Compared to the discovery correlation coefficient of 0.603 between IGF1R methylation and birth weight ratio in TwinsUK, a similar but not significant correlation was found in the DTR old (correlation coefficient $=0.263, p=0.186$ ) and NTR (correlation coeffi- cient $=0.161, p=0.132$ ) samples (Table 2). The correlation was near zero in the DTR young sample (correlation coefficient $=-0.027, p=0.888$; Table 2 ). We considered that a sex-specific effect may be present at this probe and performed sex-specific analysis. A similar positive correlation was found in both male and female subsets, suggesting that there is no sex-specific effect on the probe.

\section{Meta-Analysis at IGF1R}

We next performed a meta-analysis of the correlation coefficients between IGF1R methylation and birth weight ratio across the four birth weight discordant $\mathrm{MZ}$ samples (Table 2). We observed heterogeneity among the four samples $\left(I^{2}=83.4 \%\right)$, and therefore performed a randomeffects meta-analysis. The results showed a significant positive association (correlation coefficient $=0.282$, 95\% CI: 
-0.037, 0.550, $p=0.041$ ) between IGF1R methylation and birth weight ratio across the four studies; in total, $216 \mathrm{MZ}$ twin pairs (Figure $2 \mathrm{~B}$ ).

Compared to the TwinsUK and the DTR old samples, the DTR young and the NTR samples are much younger. The majority $(84.3 \%)$ of the MZ pairs in the DTR young sample are younger than 45 years old, whereas $84.6 \%$ of the TwinsUK pairs are older than 45 years old. Considering the age differences across the samples and the high level of heterogeneity observed across the four studies, we also performed meta-analysis across studies stratified by age. A meta-analysis of the two older age samples ( $N=98$ TwinsUK and DTR old twin pairs) did not have strong evidence for heterogeneity $\left(I^{2}=66.2 \%\right)$, and the results showed a much stronger association in the random-effects metaanalysis (correlation coefficient $=0.474$, 95\% CI: 0.099, $0.731, p=.008$ ) (Figure 2B, Table 2). Given the weak evidence for heterogeneity in the two older age samples, we therefore also performed a fixed-effects meta-analysis of these two samples and observed strong evidence for association (correlation coefficient $=0.5527,95 \%$ CI: 0.415, 0.690, $\left.p=4.59 \times 10^{-12}\right)$. These findings suggest that the observed association between birth weight and DNA methylation at the IGF1R gene is more pronounced at an older age.

\section{Discussion}

We performed epigenome-wide association analyses in whole blood samples of extreme birth weight discordant MZ twin pairs. We identified one significant differential methylation site in the IGF1R gene in the TwinsUK cohort. We observed a similar direction of effect in two independent MZ twin replication samples, and the combined meta-analysis of four twin samples showed a nominally significant association between IGF1R methylation and birth weight ratio (random-effects meta-analysis $p=.041$ ). Analyses stratified by age group indicated that the meta-analysis effect was accentuated in older twins. Although DNA methylation profiles at this $\mathrm{CpG}$ site have not been associated with age, to our knowledge (Horvath, 2013; Marttila et al., 2015; Steegenga et al., 2014), and are not associated with age in the TwinsUK sample, the mean age and age range of the four meta-analysis samples is very different and the results strongly suggest that the birth weight association effect is more pronounced at older age groups (TwinsUK and DTR old). Twin pairs from the TwinsUK cohort were also more discordant for the birth weight compared to all replication samples, and this might be an explanation for the attenuated effects observed in the replication samples, where the methylation differences in less discordant twins are modest. Our results are consistent with previous birth weight studies of the adult methylome in discordant MZ twins (Souren et al., 2013; Tan et al., 2014), that is, that there is no strong association between specific methylation signal and birth weight discordance, but moderate changes are observed.
One factor influencing the results is power to detect modest effect sizes in our study. In our previous power estimation study, a mean methylation difference of $12 \%$ was required to reach $80 \%$ power with a sample size of 71 MZ pairs (Tsai \& Bell, 2015). However, the observed MZ twin pair difference in IGF1R related to birth weight was much smaller, and corresponded to up to approximately a $3 \%$ change in the unadjusted raw DNA methylation levels. The methylation profiles reported in older MZ twins (Fraga et al., 2005) and in heritability studies (Bell et al., 2012; Gordon et al., 2012; Kaminsky et al., 2009) show that MZ twins tend to have very similar methylation patterns over the genome. This may be one reason explaining why none of the epigenetic studies in twins has identified large effects associated with birth weight.

Significant variation in the neonatal methylome occurs during early development and with changes in the intrauterine environment (Gordon et al., 2012; Levesque et al., 2014; Martino et al., 2013). Therefore, a number of studies have focused on birth weight associated methylation changes in candidate imprinted genes in both newborns and adults, and found associations in the H19 and IGF2 genes (Heijmans et al., 2008; Hoyo et al., 2012; Murphy et al., 2012). In addition to birth weight associated changes at candidate genes, epigenome-wide analyses have also explored the topranked birth weight associated signals and have identified these to be enriched for genes related to early cell and embryonic development, growth, immune system, and inflammatory response (Adkins et al., 2012; Banister et al., 2011; Engel et al., 2014; Fryer et al., 2011; Gordon et al., 2011; 2012; Simpkin et al., 2015; Straughen et al., 2015).

We observed a significant association between lower birth weight ratio and a lower methylation level at IGF1R in twins who were free from severe diseases, for example, cancer and type 2 diabetes, at the time of DNA methylation sampling, The insulin-like growth factor 1 receptor gene encodes a trans-membrane receptor that mediates the effects of IGF1 and where the receptor is activated in part by IGF2. Both IGF1 and IGF2 play a critical role in growth and have been linked to birth weight in genetic, epigenetic, and gene expression studies (Adkins et al., 2010; Heijmans et al., 2008; Koutsaki et al., 2011; McMinn et al., 2006; Ong et al., 2000; Straughen et al., 2015). Twin studies of IGF1 have found that intra-pair birth weight differences were significantly correlated with intra-pair IGF1 expression differences (Canpolat et al., 2011) and blood IGF1 concentrations (Westwood et al., 2001). Furthermore, mutations in $I G F 1 R$ can lead to abnormalities in the function of IGF1 receptors that may slow down intrauterine and subsequent growth (Abuzzahab et al., 2003). Previous work has also explored differential methylation in the IGF1R gene with birth weight. One study compared 34 maternal impaired glucose tolerance (IGT) to 106 normal glucose tolerance placentas and found that IGF1R methylation levels were significantly lower in placentas exposed to IGT (Desgagne et al., 2014). 
While it is suspected that IGF1R may have dysregulated fetal methylation levels related to birth weight, the causeeffect relationship has not been established. In our results, birth weight discordance is associated with methylation at a CpG site in intron 2 of IGF1R, which overlapped a weak ENCODE DNase signal in a number of cell types, including primary Th1T cells, suggesting potential regulatory effects. Recent preliminary work has also reported that gene expression levels of $I G F 1 R$ were significantly lower in placentas from healthy mothers of term newborns who were of small gestational age (Lazo-de-la-Vega-Monroy et al., 2015), although this association was not observed in chorionic villus samples (Demetriou et al., 2014). Our findings therefore complement these results, and suggest that some of these effects may also be observed in the fetus and could be epigenetically mediated.

The pathways leading to LBW and birth weight discordance in twins may arise through mechanisms that are not experienced by singletons (Lopriore et al., 2003). Generally, singletons and twins develop at a similar rate until the 30th week of gestation, after which point uterine restriction is a major contributing factor to twin birth weight (ClearyGoldman \& D'Alton, 2008). A lighter MZ twin has a greater likelihood of being genuinely growth restricted compared to their co-twin (Torche \& Echevarria, 2011). Birth weight differences in twins are thought to originate from multiple factors, including differences in fetal access to nutrition, which can be affected by the position of fetus in utero, as well as the umbilical cord. Twin-to-twin transfusion syndrome (TTTS) is another potential cause of the birth weight discordance in twins. The prevalence of TTTS is relatively low on average (1-3 per 10,000 births), but is greater in monochorionic twins, and can account for up to $17 \%$ of the total perinatal morality in twins, and $50 \%$ of death in MCDA twins (Steinberg et al., 1990; Lewi et al., 2008).

There are several limitations in our study. First, birth weight or body weight is a complex phenotype, and the exact contribution of genetic and epigenetic variation to it, and extent of its shared effects with late-onset diseases, remains largely unknown. We used $M Z$ twin pairs in the study to minimize the impact of genetic variation. Second, the sample size was moderate, and given the observed small effect at the top-ranked signal, larger samples will be needed to reach sufficient power. Third, information on the chronicity of the twin pairs was not available, and previous studies have reported that MZ MC (monochorionic: twins that share a single placenta) twins have a more imbalanced nutrient supply than the MZ DC (dichorionic: twins with two separate placentas) twins (Derom et al., 2006). Fourth, the birth weight information in the TwinsUK cohort was self-reported, which could potentially influence the intrapair discordance and effect estimates. Lastly, although our study identifies a significant association between LBW and a DNA methylation change in the IGF1R gene, which is highly relevant to growth, we cannot rule out the potential effects of reverse causation or confounding on the findings. Although the twins included in our sample are self-reported to be free from severe disease, this is not necessarily a reflection of their entire post-natal health and environmental exposures in early life and over the life course. Longitudinal epigenetic studies in twins would be the ideal study design to assess the epigenetic signature of birth weight discordance and its health impacts over the life course.

\section{Conclusion}

We found one genome-wide significant differential methylation signal in the IGF1R gene in discordant identical twin pairs, assessed many years after birth, which was confirmed in a meta-analysis of four independent twin samples. Our findings in adult twins suggest that methylation changes associated with prenatal conditions such as LBW may persist over time, but that the observed effects tend to be relatively modest.

\section{Acknowledgments}

We would like to thank all twins and family members in the TwinsUK cohort, the NTR, and the DTR.

TwinsUK: Support for this work was obtained from the European Research Council (ERC 250157) and in part from the TwinsUK resource, which is funded by the Wellcome Trust; the European Community's Seventh Framework Programme (FP7/2007-2013); and the National Institute for Health Research (NIHR) BioResource, Clinical Research Facility and Biomedical Research Centre based at Guy's and St Thomas' NHS Foundation Trust and King's College London.

NTR: We would like to thank the funding agencies for their support, including the Netherlands Organization for Scientific Research (NWO 900-562-137, 904-61-090, 985-10-002, 904-61-193, 56-464-14192, 400-03-330, 480-04-004, 40007-080, 911-09-032, 451-06-004, 451-08-026, 451-10-005), the BBRMI-NL -financed BIOS Consortium (NWO 184.021.007), the Netherlands Organization for Health Research and Development (ZonMW 3100.0038, 940-37024, 31160008), EMGO+ Institute for Health and Care Research, Neuroscience Campus Amsterdam, BBMRI-NL (184.021.007: Biobanking and Biomolecular Resources Research Infrastructure), National Institutes of Health (NIH 5R37DA018673-03, R01 MH059160, 1RC2 MH089951-01, 4R37DA018673-06, 1R01 MH087646-01A1), National Institute of Mental Health (RFA MH08120), Brain and Behavior Research Foundation (2011 NARSAD Distinguished Investigator Grant; 18633), FP7 ENGAGE (FP7-HEALTH-F4-2007-201413), European Research 
Council (230374-GMI, 284167), Rutgers University (3797).

DTR: This work was supported by the Integrated research on DEvelopmental determinants of Aging and Longevity (IDEAL), an EU's FP7 project with number: 259679. The Danish Twin Registry is supported by a grant from The National Program for Research Infrastructure 2007 from the Danish Agency for Science Technology and Innovation.

\section{References}

Abuzzahab, M. J., Schneider, A., Goddard, A., Grigorescu, F., Lautier, C., \& Keller, E. (2003). Intrauterine growth retardation study group. IGF-I receptor mutations resulting in intrauterine and postnatal growth retardation. New England Journal of Medicine, 349, 2211-2222.

Adkins, R. M., Somes, G., Morrison, J. C., Hill, J. B., Watson, E. M., Magann, E. F., \& Krushkal, J. (2010). Association of birth weight with polymorphisms in the IGF2, H19, and IGF2R genes. Pediatric Research, 68, 429-434.

Adkins, R. M., Tylavsky, F. A., \& Krushkal, J. (2012). Newborn umbilical cord blood DNA methylation and gene expression levels exhibit limited association with birth weight. Chemistry and Biodiversity, 9, 888-899.

Amarasekera, M., Noakes, P., Strickland, D., Saffery, R., Martino, D. J., \& Prescott, S. L. (2014). Epigenome-wide analysis of neonatal CD4(+) T-cell DNA methylation sites potentially affected by maternal fish oil supplementation. Epigenetics, 9, 1570-1576.

Aryee, M. J., Jaffe, A. E., Corrada-Bravo, H., Ladd-Acosta, C., Feinberg, A. P., Hansen, K. D., \& Irizarry, R. A. (2014). Minfi: A flexible and comprehensive bioconductor package for the analysis of infinium DNA methylation microarrays. Bioinformatics, 30, 1363-1369.

Baird, J., Osmond, C., MacGregor, A., Snieder, H., Hales, C. N., \& Phillips, D. I. (2001). Testing the fetal origins hypothesis in twins: The birmingham twin study. Diabetologia, 44, 33-39.

Banister, C. E., Koestler, D. C., Maccani, M. A., Padbury, J. F., Houseman, E. A., \& Marsit, C. J. (2011). Infant growth restriction is associated with distinct patterns of DNA methylation in human placentas. Epigenetics, 6, 920-927.

Barker, D. J. (2004). The developmental origins of adult disease. Journal of the American College of Nutrition, 23, 588S595 .

Barker, D. J., Hales, C. N., Fall, C. H., Osmond, C., Phipps, K., \& Clark, P. M. (1993a). Type 2 (non-insulin-dependent) diabetes mellitus, hypertension and hyperlipidaemia (syndrome X): Relation to reduced fetal growth. Diabetologia, $36,62-67$.

Barker, D. J., \& Osmond, C. (1986). Infant mortality, childhood nutrition, and ischaemic heart disease in England and Wales. Lancet, 1(8489), 1077-1081.

Barker, D. J., Osmond, C., Simmonds, S. J., \& Wield, G. A. (1993b). The relation of small head circumference and thinness at birth to death from cardiovascular disease in adult life. BMJ, 306, 422-426.
Barker, D. J., Winter, P. D., Osmond, C., Margetts, B., \& Simmonds, S. J. (1989). Weight in infancy and death from ischaemic heart disease. Lancet, 2(8663), 577-580.

Battaglia, F. C., \& Lubchenco, L. O. (1967). A practical classification of newborn infants by weight and gestational age. Journal of Pediatrics, 71, 159-163.

Bell, J. T., Tsai, P. C., Yang, T. P., Pidsley, R., Nisbet, J., Glass, D., \& Deloukas, P. (2012). Epigenome-wide scans identify differentially methylated regions for age and age-related phenotypes in a healthy ageing population. PLoS Genetics, 8, e1002629.

Boomsma, D. I., de Geus, E. J., Vink, J. M., Stubbe, J. H., Distel, M. A., Hottenga, J. J., \& Willemsen, G. (2006). Netherlands twin register: From twins to twin families. Twin Research and Human Genetics, 9, 849-857.

Boomsma, D. I., Vink, J. M., van Beijsterveldt, T. C., de Geus, E. J., Beem, A. L., Mulder, E. J., \& van Baal, G. C. (2002). Netherlands twin register: A focus on longitudinal research. Twin Research, 5, 401-406.

Brennan, A., Meng, Y., Holmes, J., Hill-McManus, D., \& Meier, P. S. (2014). Potential benefits of minimum unit pricing for alcohol versus a ban on below cost selling in England 2014: Modelling study. BMJ, 349, g5452.

Brooks, A. M., Byrd, R. S., Weitzman, M., Auinger, P., \& McBride, J. T. (2001). Impact of low birth weight on early childhood asthma in the United States. Archives of Pediatrics and Adolescent Medicine, 155, 401-406.

Canpolat, F. E., Cekmez, F., Sarici, S. U., Korkmaz, A., \& Yurdakok, M. (2011). Insulin-like growth factor-1 levels in twins and its correlation with discordance. Twin Research and Human Genetics, 14, 94-97.

Clausson, B., Lichtenstein, P., \& Cnattingius, S. (2000). Genetic influence on birthweight and gestational length determined by studies in offspring of twins. BJOG, 107, 375-381.

Cleary-Goldman, J., \& D’Alton, M. E. (2008). Growth abnormalities and multiple gestations. Seminars in Perinatology, 32, 206-212.

Demetriou, C., Abu-Amero, S., Thomas, A. C., Ishida, M., Aggarwal, R., Al-Olabi, L., \& Moore, G. E. (2014). Paternally expressed, imprinted insulin-like growth factor-2 in chorionic villi correlates significantly with birth weight. PLoS One, 9, e85454.

Derom, C. A., Vlietinck, R. F., Thiery, E. W., Leroy, F. O., Fryns, J. P., \& Derom, R. M. (2006). The east flanders prospective twin survey (EFPTS). Twin Research and Human Genetics, 9, 733-738.

Desgagne, V., Hivert, M. F., St-Pierre, J., Guay, S. P., Baillargeon, J. P., Perron, P., \& Bouchard, L. (2014). Epigenetic dysregulation of the IGF system in placenta of newborns exposed to maternal impaired glucose tolerance. Epigenomics, 6, 193-207.

Dominguez-Salas, P., Moore, S. E., Baker, M. S., Bergen, A. W., Cox, S. E., Dyer, R. A., \& Hennig, B. J. (2014). Maternal nutrition at conception modulates DNA methylation of human metastable epialleles. Nature Communications, 5, 3746.

Engel, S. M., Joubert, B. R., Wu, M. C., Olshan, A. F., Haberg, S. E., Ueland, P. M., \& London, S. J. (2014). 
Neonatal genome-wide methylation patterns in relation to birth weight in the Norwegian mother and child cohort. American Journal of Epidemiology, 179, 834842.

Fagerberg, B., Bondjers, L., \& Nilsson, P. (2004). Low birth weight in combination with catch-up growth predicts the occurrence of the metabolic syndrome in men at late middle age: The Atherosclerosis and insulin resistance study. Journal of Internal Medicine, 256, 254-259.

Fernandez-Twinn, D. S., \& Ozanne, S. E. (2010). Early life nutrition and metabolic programming. Annals of the New York Academy of Sciences, 1212, 78-96.

Filiberto, A. C., Maccani, M. A., Koestler, D., WilhelmBenartzi, C., Avissar-Whiting, M., Banister, C. E., Gagne, L. A., ... Marsit, C. J. (2011). Birthweight is associated with DNA promoter methylation of the glucocorticoid receptor in human placenta. Epigenetics, 6, 566-572.

Fortin, J. P., Labbe, A., Lemire, M., Zanke, B. W., Hudson, T. J., Fertig, E. J., Greenwood, C. M., ... Hansen, K. D. (2014). Functional normalization of 450k methylation array data improves replication in large cancer studies. Genome Biology, 15, 503.

Fraga, M. F., Ballestar, E., Paz, M. F., Ropero, S., Setien, F., Ballestar, M. L., \& Esteller, M. (2005). Epigenetic differences arise during the lifetime of monozygotic twins. Proceedings of the National Academy of Sciences of the United States of America, 102, 10604-10609.

Freathy, R. M., Mook-Kanamori, D. O., Sovio, U., Prokopenko, I., Timpson, N. J., Berry, D. J., \& McCarthy, M. I. (2010). Variants in ADCY5 and near CCNL1 are associated with fetal growth and birth weight. Nature Genetics, 42, 430435.

Frost, M., Petersen, I., Brixen, K., Beck-Nielsen, H., Holst, J. J., Christiansen, L., Hojlund, K., ... Christensen, K. (2012). Adult glucose metabolism in extremely birthweightdiscordant monozygotic twins. Diabetologia, 55, 32043212.

Fryer, A. A., Emes, R. D., Ismail, K. M., Haworth, K. E., Mein, C., Carroll, W. D., \& Farrell, W. E. (2011). Quantitative, high-resolution epigenetic profiling of $\mathrm{CpG}$ loci identifies associations with cord blood plasma homocysteine and birth weight in humans. Epigenetics, 6, 86-94.

Gielen, M., Lindsey, P. J., Derom, C., Smeets, H. J., Souren, N. Y., Paulussen, A. D., Derom, R., ... Nijhuis, J. G. (2008). Modeling genetic and environmental factors to increase heritability and ease the identification of candidate genes for birth weight: A twin study. Behavior Genetics, 38, 4454.

Gordon, L., Joo, J. E., Powell, J. E., Ollikainen, M., Novakovic, B., Li, X., \& Saffery, R. (2012). Neonatal DNA methylation profile in human twins is specified by a complex interplay between intrauterine environmental and genetic factors, subject to tissue-specific influence. Genome Research, 22, 1395-1406.

Gordon, L., Joo, J. H., Andronikos, R., Ollikainen, M., Wallace, E. M., Umstad, M. P., \& Craig, J. M. (2011). Expression discordance of monozygotic twins at birth: effect of intrauterine environment and a possible mechanism for fetal programming. Epigenetics, 6, 579-592.
Heijmans, B. T., Tobi, E. W., Stein, A. D., Putter, H., Blauw, G. J., Susser, E. S., Slagboom, P. E., ... Lumey, L. H. (2008). Persistent epigenetic differences associated with prenatal exposure to famine in humans. Proceedings of the National Academy of Sciences of the United States of America, 105, 17046-17049.

Higgins, J. P., \& Thompson, S. G. (2002). Quantifying heterogeneity in a meta-analysis. Statistics in Medicine, 21, 15391558.

Horikoshi, M., Yaghootkar, H., Mook-Kanamori, D. O., Sovio, U., Taal, H. R., Hennig, B. J., \& Freathy, R. M. (2013). New loci associated with birth weight identify genetic links between intrauterine growth and adult height and metabolism. Nature Genetics, 45, 76-82.

Horvath, S. (2013). DNA methylation age of human tissues and cell types. Genome Biology, 14, R115.

Houseman, E. A., Accomando, W. P., Koestler, D. C., Christensen, B. C., Marsit, C. J., \& Kelsey, K. T. (2012). DNA methylation arrays as surrogate measures of cell mixture distribution. BMC Bioinformatics, 13, 86.

Hoyo, C., Fortner, K., Murtha, A. P., Schildkraut, J. M., Soubry, A., Demark-Wahnefried, W., \& Murphy, S. K. (2012). Association of cord blood methylation fractions at imprinted insulin-like growth factor 2 (IGF2), plasma IGF2, and birth weight. Cancer Causes Control, 23, 635-645.

Jarvelin, M. R., Sovio, U., King, V., Lauren, L., Xu, B., McCarthy, M. I., \& Elliott, P. (2004). Early life factors and blood pressure at age 31 years in the 1966 northern Finland birth cohort. Hypertension, 44, 838-846.

Johansson, S., Iliadou, A., Bergvall, N., de Faire, U., Kramer, M. S., Pawitan, Y., \& Cnattingius, S. (2008). The association between low birth weight and type 2 diabetes: Contribution of genetic factors. Epidemiology, 19, 659-665.

Kaminsky, Z. A., Tang, T., Wang, S. C., Ptak, C., Oh, G. H., Wong, A. H., \& Petronis, A. (2009). DNA methylation profiles in monozygotic and dizygotic twins. Nature Genetics, 41, 240-245.

Koutsaki, M., Sifakis, S., Zaravinos, A., Koutroulakis, D., Koukoura, O., \& Spandidos, D. A. (2011). Decreased placental expression of hPGH, IGF-I and IGFBP-1 in pregnancies complicated by fetal growth restriction. Growth Hormone \& IGF Research, 21, 31-36.

Kramer, M. S. (1987a). Determinants of low birth weight: Methodological assessment and meta-analysis. Bulletin of the World Health Organization, 65, 663-737.

Kramer, M. S. (1987b). Intrauterine growth and gestational duration determinants. Pediatrics, 80, 502-511.

Laliberté, E. (2011). Metacor: Meta-analysis of correlation coefficients. R package version 1.0-2. Retrieved from http://CRAN.R-project.org/package=metacor.

Lazo-de-la-Vega-Monroy, M.-L., González-Domínguez, M. I., Daza-Benítez, L., \& Barbosa-Sabanero, G. (2015). Placental IGF1R-PI3 K/AK/Akt pathway and its relationship to 1 idiopathic birth weight alterations. Paper presented at the Society for Endocrinology ECE 2015, Endocrine, Dublin, Ireland.

Leeson, C. P., Kattenhorn, M., Morley, R., Lucas, A., \& Deanfield, J. E. (2001). Impact of low birth weight and 
cardiovascular risk factors on endothelial function in early adult life. Circulation, 103, 1264-1268.

Levesque, M. L., Casey, K. F., Szyf, M., Ismaylova, E., Ly, V., Verner, M. P., \& Booij, L. (2014). Genome-wide DNA methylation variability in adolescent monozygotic twins followed since birth. Epigenetics, 9, 1410-1421.

Lewi, L., Jani, J., Blickstein, I., Huber, A., Gucciardo, L., Van Mieghem, T., \& Deprest, J. (2008). The outcome of monochorionic diamniotic twin gestations in the era of invasive fetal therapy: A prospective cohort study. American Journal of Obstetrics and Gynecology, 199, 514, e511-518.

Loke, Y. J., Novakovic, B., Ollikainen, M., Wallace, E. M., Umstad, M. P., Permezel, M., \& Craig, J. M. (2013). The peri/postnatal epigenetic twins study (PETS). Twin Research and Human Genetics, 16, 13-20.

Lopriore, E., Nagel, H. T., Vandenbussche, F. P., \& Walther, F. J. (2003). Long-term neurodevelopmental outcome in twin-to-twin transfusion syndrome. American Journal of Obstetrics and Gynecology, 189, 1314-1319.

Lunde, A., Melve, K. K., Gjessing, H. K., Skjaerven, R., \& Irgens, L. M. (2007). Genetic and environmental influences on birth weight, birth length, head circumference, and gestational age by use of population-based parent-offspring data. American Journal of Epidemiology, 165, 734-741.

Magnus, P. (1984a). Causes of variation in birth weight: A study of offspring of twins. Clinical Genetics, 25, 15-24.

Magnus, P. (1984b). Further evidence for a significant effect of fetal genes on variation in birth weight. Clinical Genetics, 26, 289-296.

Magnus, P., Gjessing, H. K., Skrondal, A., \& Skjaerven, R. (2001). Paternal contribution to birth weight. Journal of Epidemiology and Community Health, 55, 873-877.

Maksimovic, J., Gordon, L., \& Oshlack, A. (2012). SWAN: Subset-quantile within array normalization for illumina infinium HumanMethylation 450 beadchips. Genome Biology, 13, R44.

Martino, D., Loke, Y. J., Gordon, L., Ollikainen, M., Cruickshank, M. N., Saffery, R., \& Craig, J. M. (2013). Longitudinal, genome-scale analysis of DNA methylation in twins from birth to 18 months of age reveals rapid epigenetic change in early life and pair-specific effects of discordance. Genome Biology, 14, R42.

Marttila, S., Kananen, L., Hayrynen, S., Jylhava, J., Nevalainen, T., Hervonen, A., \& Hurme, M. (2015). Ageing-associated changes in the human DNA methylome: Genomic locations and effects on gene expression. BMC Genomics, 16, 179.

McCormick, M. (1985). The contribution of low birth weight to infant mortality and childhood morbidity. New England Journal of Medicine, 312, 82-90.

McIntire, D. D., Bloom, S. L., Casey, B. M., \& Leveno, K. J. (1999). Birth weight in relation to morbidity and mortality among newborn infants. New England Journal of Medicine, 340, 1234-1238.

McMinn, J., Wei, M., Schupf, N., Cusmai, J., Johnson, E. B., Smith, A. C., Weksberg, R., ... Tycko, B. (2006). Unbalanced placental expression of imprinted genes in human intrauterine growth restriction. Placenta, 27, 540549 .
McNeill, G., Tuya, C., \& Smith, W. C. (2004). The role of genetic and environmental factors in the association between birthweight and blood pressure: Evidence from metaanalysis of twin studies. International Journal of Epidemiology, 33, 995-1001.

Moayyeri, A., Hammond, C. J., Valdes, A. M., \& Spector, T. D. (2013). Cohort profile: TwinsUK and healthy ageing twin study. International Journal of Epidemiology, 42, 7685.

Mook-Kanamori, D. O., van Beijsterveldt, C. E., Steegers, E. A., Aulchenko, Y. S., Raat, H., Hofman, A., Eilers, P. H., ... Jaddoe, V. W. (2012). Heritability estimates of body size in fetal life and early childhood. PLoS One, 7, e39901.

Mulligan, C. J., D’Errico, N. C., Stees, J., \& Hughes, D. A. (2012). Methylation changes at NR3C1 in newborns associate with maternal prenatal stress exposure and newborn birth weight. Epigenetics, 7, 853-857.

Murphy, R., Ibanez, L., Hattersley, A., \& Tost, J. (2012). IGF2/H19 hypomethylation in a patient with very low birthweight, precocious pubarche and insulin resistance. BMC Medical Genetics, 13, 42.

Ollikainen, M., Smith, K. R., Joo, E. J., Ng, H. K., Andronikos, R., Novakovic, B., Abdul, A., ... Craig, J. M. (2010). DNA methylation analysis of multiple tissues from newborn twins reveals both genetic and intrauterine components to variation in the human neonatal epigenome. Human Molecular Genetics, 19, 4176-4188.

Ong, K., Kratzsch, J., Kiess, W., Costello, M., Scott, C., \& Dunger, D. (2000). Size at birth and cord blood levels of insulin, insulin-like growth factor I (IGF-I), IGF-II, IGFbinding protein-1 (IGFBP-1), IGFBP-3, and the soluble IGF-II/mannose-6-phosphate receptor in term human infants. The ALSPAC study team. Avon longitudinal study of pregnancy and childhood. Journal of Clinical Endocrinology \& Metabolism, 85, 4266-4269.

Re, A. C. D., \& Hoyt, W. T. (2012). MAc: Meta-analysis with correlations. R package version 1.1. http://CRAN. R-project.org/package $=$ MAc.

Schulze, R. (2004). Meta-Analysis: A Comparison of Approaches. Cambridge, MA: Hogrefe \& Huber.

Simpkin, A. J., Suderman, M., Gaunt, T. R., Lyttleton, O., McArdle, W. L., Ring, S. M., \& Relton, C. L. (2015). Longitudinal analysis of DNA methylation associated with birth weight and gestational age. Human Molecular Genetics, 24, 3752-3763.

Souren, N. Y., Lutsik, P., Gasparoni, G., Tierling, S., Gries, J., Riemenschneider, M., \& Walter, J. (2013). Adult monozygotic twins discordant for intra-uterine growth have indistinguishable genome-wide DNA methylation profiles. Genome Biology, 14, R44.

Steegenga, W. T., Boekschoten, M. V., Lute, C., Hooiveld, G. J., de Groot, P. J., Morris, T. J., \& Muller, M. (2014). Genomewide age-related changes in DNA methylation and gene expression in human PBMCs. Age, 3, 9648.

Steegers-Theunissen, R. P., Obermann-Borst, S. A., Kremer, D., Lindemans, J., Siebel, C., Steegers, E. A., Slagboom, P. E., ... Heijmans, B. T. (2009). Periconceptional maternal folic acid use of 400 microg per day is related to increased 
methylation of the IGF2 gene in the very young child. PLoS One, 4, e7845.

Steinberg, L. H., Hurley, V. A., Desmedt, E., \& Beischer, N. A. (1990). Acute polyhydramnios in twin pregnancies. Australian and New Zealand Journal of Obstetrics and Gynaecology, 30, 196-200.

Straughen, J. K., Sipahi, L., Uddin, M., Misra, D. P., \& Misra, V. K. (2015). Racial differences in IGF1 methylation and birth weight. Clinical Epigenetics, 7, 47.

Tan, Q., Frost, M., Heijmans, B. T., von Bornemann Hjelmborg, J., Tobi, E. W., Christensen, K., \& Christiansen, L. (2014). Epigenetic signature of birth weight discordance in adult twins. BMC Genomics, 15, 1062.

Teschendorff, A. E., Marabita, F., Lechner, M., Bartlett, T., Tegner, J., Gomez-Cabrero, D., \& Beck, S. (2013). A betamixture quantile normalization method for correcting probe design bias in Illumina Infinium 450k DNA methylation data. Bioinformatics, 29, 189-196.

Thompson, C., Syddall, H., Rodin, I., Osmond, C., \& Barker, D. J. (2001). Birth weight and the risk of depressive disorder in late life. British Journal of Psychiatry, 179, 450-455.

Torche, F., \& Echevarria, G. (2011). The effect of birthweight on childhood cognitive development in a middle-income country. International Journal of Epidemiology, 40, 10081018.

Tsai, P. C., \& Bell, J. T. (2015). Power and sample size estimation for epigenome-wide association scans to detect differential DNA methylation. International Journal of Epidemiology. Advance online publication.

Tsaprouni, L. G., Yang, T. P., Bell, J., Dick, K. J., Kanoni, S., Nisbet, J., \& Deloukas, P. (2014). Cigarette smoking reduces DNA methylation levels at multiple genomic loci but the effect is partially reversible upon cessation. Epigenetics, 9, 1382-1396.

van Dongen, J., Ehli, E. A., Slieker, R. C., Bartels, M., Weber, Z. M., Davies, G. E., \& Boomsma, D. I. (2014). Epigenetic variation in monozygotic twins: A genome-wide analysis of DNA methylation in buccal cells. Genes, 5, 347-365. van Dongen, J., Nivard, M. G., Willemsen, G., Hottenga, J.-J., Helmer, Q., Dolan, C. V., Ehli, E. A., ... Boomsma, D. I. (under review) Genetic and environmental influences interact with age and sex in shaping the human methylome.

Walter, E. C., Ehlenbach, W. J., Hotchkin, D. L., Chien, J. W., \& Koepsell, T. D. (2009). Low birth weight and respiratory disease in adulthood: A population-based case-control study. American Journal of Respiratory and Critical Care Medicine, 180, 176-180.

Ward, C., Lewis, S., \& Coleman, T. (2007). Prevalence of maternal smoking and environmental tobacco smoke exposure during pregnancy and impact on birth weight: Retrospective study using Millennium Cohort. BMC Public Health, 7,81 .

Westwood, M., Gibson, J. M., Sooranna, S. R., Ward, S., Neilson, J. P., \& Bajoria, R. (2001). Genes or placenta as modulator of fetal growth: Evidence from the insulin-like growth factor axis in twins with discordant growth. Molecular Human Reproduction, 7, 387-395.

Willemsen, G., de Geus, E. J., Bartels, M., van Beijsterveldt, C. E., Brooks, A. I., Estourgie-van Burk, G. F., \& Boomsma, D. I. (2010). The netherlands twin register biobank: A resource for genetic epidemiological studies. Twin Research and Human Genetics, 13, 231-245.

Willemsen, G., Vink, J. M., Abdellaoui, A., den Braber, A., van Beek, J. H., Draisma, H. H., \& Boomsma, D. I. (2013). The adult netherlands twin register: Twenty-five years of survey and biological data collection. Twin Research and Human Genetics, 16, 271-281.

World Health Organization. (1992). The ICD-10 classification of mental and behavioural disorders: Clinical descriptions and diagnostic guidelines. Geneva: Author.

Wu, Y. W., Xing, G., Fuentes-Afflick, E., Danielson, B., Smith, L. H., \& Gilbert, W. M. (2011). Racial, ethnic, and socioeconomic disparities in the prevalence of cerebral palsy. Pediatrics, 127, e674-681. 